\title{
New Forms and Functions of Subordinate Clause in Kurdish
}

Kürtçede yan cümleciklerin yeni biçim ve işlevleri

\section{Hewa Salam Khalid ${ }^{1}$, Atta Mostafa Hamamorad ${ }^{2}$}

\begin{abstract}
Kurdish is an agglutinative language, so that subject and object might appear as a dependent morpheme, and sometimes they would become a zero morpheme and disappear in sentence, but still they have obvious meaning. Kurdish speaker can distinguish between the meanings of sentences that consist in same word, but have different gist, because of rhythm. However, it becomes more challenging in writing and grammatical analyzes. Moreover, this complexity is advance more in complex sentences, which is concentrated on in this article. There are various classifications for Kurdish subordinate clause in terms of semantic. They highlighted the meaning of sentences. So that the categorizations are different with each other, and each linguist shows its opinion due to the fact that meaning is tricky itself, and would change easily with context. To be more accurate, in this study, Kurdish subordinate clause will be classified in terms of syntax, which is static.
\end{abstract}

Keywords: Kurdish grammar, lexical clauses, simple sentence, compound sentence, complex sentence

\section{Kurte}

Kurdî zmanêkî lkawye, leber ewe bker w berkar lewaneye wek morfîmî yarîdeder le risteda derbkewn, tenanet hendêkcar debne morfîmî sifr w dernakewn, legel eweşda hestyan pê dekrêt le ruî manawe. Qsekerî Kurd detwanêt cyawazî bkat le nêwan manaî ew rstaney ke le heman wşe pêk hatwn w watay cyawazyan heye, be hoy awazî qsekirdnewe. Herçende em cyakrdneweye kemêk grantr debêt le katî nusîn w şîkrdnewey rêzmanî. Tenanet em alozye zyatrîş debêt lê rstey alozda, ke lem lêkolîneweyeda tîşkî xrawete ser. Dabeşkirdnî corawcorman heye le rwangey sîmantîkyewe bo larista le zmanî Kurdî da, ke grngyan be watay riste dawe. Le encamda polênkrdnekan cyawazn la yektir w her zmanewanêk ray xoy le barewe derbrîwe. Çunke xoy le xoyda mana negor nye w zor be asanî gorankarî beser dêt le jîngeî axawtn. Lem lêkolîneweye da larista polên krawe be gwêrey erke rêzmanyekey, ke em dabeşkirdne deşêt wrdtir w negortir bêt.

Peyvên Serekê: Rêzmanî Kurdî, amrazekanî bestnewe, ristaî sade, ristâ̂ lêkdraw, ristaî aloz.

Recommended citation:

Khalid, H. S. \& Hamamorad, A. M. (2015). New Forms and Functions of Subordinate Clause in Kurdish. International Journal of Kurdish Studies 1 (2), pp.1 - 14.

\footnotetext{
${ }^{1}$ Corresponding Author: Koya University Kurdish Department -- Kurdistan Region of Iraq E-mail: hewa.salam@koyauniversity.org

${ }^{2}$ Halabja University English Department — Kurdistan Region, E-mail: atta.hawrami82@ gmail.com
} 


\section{INTRODUCTION}

Studies of Kurdish language are generally focused on language family, Kurdish dialects, language policy and so on. There is not enough works in the field of Kurdish grammar, in particular in English language. It might be because Kurdish is not standardized and each dialect works in its own.

Due of the fact that Kurdish is an agglutinative language, considerate the construction of Kurdish sentence would be challenging for speakers of some other languages, for example English speakers. This is because both subject and object might be agglutinated and appear as a dependent morpheme, and in some cases the dependent morpheme will not appear. So that, there can be only one word that have proper meaning and work as a complete sentence because of its zero morpheme. Zero morpheme is a hidden morpheme that is not appeared, but still have a role and meaning in a sentence. In contrast, English sentences need to have independent subject, object and verb. Furthermore, compound and complex sentences also need to be analyzed and categorized by considering other parts of sentence such as lexical clauses.

Likewise other languages, there are two kinds of categorizations of Kurdish sentences. The first one, which are the traditional works, classifies Kurdish sentences in terms of meaning. For example, Declarative, Interrogative, Imperative and Exclamatory sentences, which sometimes might be problematic, because meaning would be tricky and it would change depending on the context. The second one concentrates more on the structure of sentence, such as simple sentence, compound sentence and complex sentence. Then, there would be cohesive understanding due to the fact that structure is more obvious and concrete than meaning; however, meaning also needs to be taken into account. These analytical types are seen in categorizing subordinate clause as well. Those who classify subordinate clauses in terms of meaning have dissimilar classifications. For example the classification of Zare Yusupova is different with the classification of Nuri Ali Amin, and they are different from the classification of Kurdistan Mukriani, and so on (Yusupova, 2005; Amin, 1960; Mukryani, 2004). The question is "Could subordinate clauses be classified in terms of grammar?" and "How accurate is it?"

The study presents a qualitative analysis of subordinate clause in Kurdish language 'Central Kurmanji dialect - Sorani'. To have deeper understanding, the examples are defined, translated, and compared to English grammar. Also the changes, in particular morphosyntax changes, are presented within smart arts. Types of subordinate clause are classified in terms of grammatical structure, and they were compared with types that categorized in terms of meaning.

In general, excluding introduction and conclusion, the study consists of two main parts; the first part is sentence in Kurdish language. In this part, various descriptions for sentences are analyzed, and Kurdish sentences is compared with sentences in English. Then, forms of Kurdish sentences are classified in terms of meaning and structure. Also, types of lexical clause are presented. The second part focuses on the classification of Kurdish subordinate clause in terms of grammatical structure. 


\section{Sentence in Kurdish language}

Generally, there are various definitions for a sentence, and each comes from a special point of view, or it is defined according to a particular language. For example sentence is defined as 'a set of words that is complete in itself, typically containing a subject and predicate, conveying a statement, question, exclamation, or command, and consisting of a main clause and sometimes one or more subordinate clauses' (Oxford Dictionary, 2015). This definition is totally acceptable for English language, but it might not be appropriate for some other languages that difference with English, for example Kurdish language. This is because the structure of Kurdish language is grammatically different from English language. So, one needs to look for Kurdish linguistic definitions for sentence to understand more about it in Kurdish. There are fundamental differences between the two languages, for example; standard word order in Kurdish is SOV, while English standard word order is SVO (Bybee, 2002, p. 4). Also, Kurdish language is an agglutinative language, which means that Kurdish sentence may consist of only one word, whereas the definition of sentence in English language confirm that it is a combination of 'a set of words' as mentioned above. To be more obvious, take these Kurdish sentences and their meanings in English as examples:

- /ha:t/ means: He/She came.

/rorift/ means: He/She went.

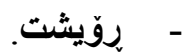

In Kurdish sentences, subject has not appeared as an independent morpheme, however, Kurdish speaker still sense the meaning of hidden morpheme. Regarding English sentences, they have an independent subject.

To cover Kurdish sentences within a definition, Kurdish linguists suggest various definitions for sentence. Some of these definitions looked at Kurdish sentence semantically, for example sentence is defined by Tofiq Wahbi as 'set of words that have complete meaning' (Mukiryani, 2002, p. 8). Also, Nuri Ali Hama-Amin says; 'when we are speaking or writing, some morphemes will be used, they have proper meaning, and there will be a verb' (Amin, 1960, p. 37). Both Kurdish definitions almost express similar idea and they might have gotten benefit from the English definitions or the definition for sentence in other languages. Moreover, they have concentrated on meaning of sentence, so they would not be wildly accurate due to the fact that meaning is very tricky, and it often depends on context. On the other hand, there are grammatical definitions for a Kurdish sentence. Muhamad Maruf Fattah's view can be taken as an example, who argued that; 'sentence is the biggest item in syntax that is independent in terms of construction' (Fattah, 1990, p. 98). It is believed that this definition is more appropriate for Kurdish sentences, it encompasses all types, and it brings back sentence into syntax.

Regarding the types of sentences, similar with other languages, there are two kinds of classifications for Kurdish sentence. On one hand, sentences are classified in terms of 
meaning (Mukiryani, 2002; Kakil, 1995) that they generally are categorized in four functional parts, which are:

1. Declarative sentence:

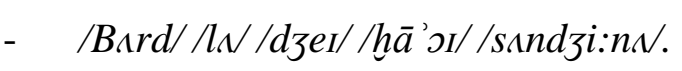

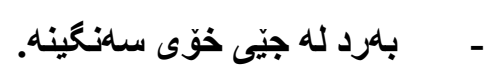

(Stone is heavy in its place. $^{3}$ )

2. Interrogative sentence:

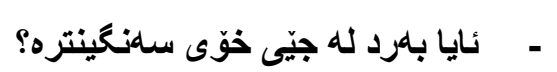

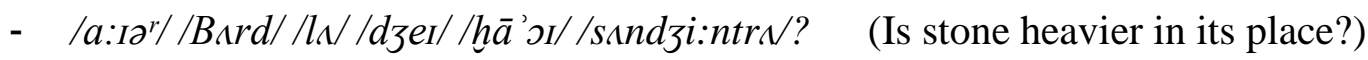

3. Imperative sentence:

- /ım//ka:ra//bkN.

(Do this work.)

4. Exclamatory sentence

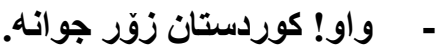

- /wa:w/! /Kwrdstan//zoor//dzwand/. (Wow! Kurdistan is very beautiful.)

Also, it might be important to say that the harmony of the speaker has a great role in changing meaning of Kurdish sentence. One would not need any extra morpheme to change the meaning of a sentence. The bottom sentences, can be changed just by harmony without any grammatical change, however, it is recommended to use the keys in formal places.

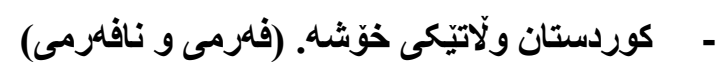

/Kwrdsta:n//wlatekI//hä'ovfN(Formal and informal).

(Kurdistan is a beautiful country.)

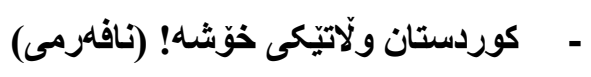

/Kwrdsta:n//wlatekI//hä'ovfN! (Informal).

(Kurdistan is a beautiful country!)

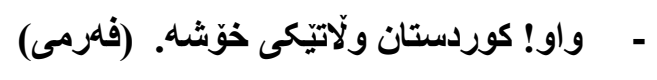

/wa:w/!/Kwrdsta:n//wlateki//hä'ovfN. (Informal).

(Wow! Kurdistan is a beautiful country.)

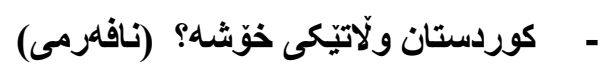

/Kwrdsta:n//wlatekI//hä'ovfs? (Informal).

(Is Kurdistan a beautiful country?)

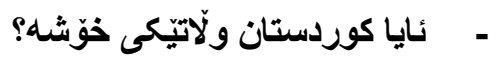

/a:Ia//Kwrdsta:n//wlatekI//hä'ovfN? (Informal).

\footnotetext{
${ }^{3}$ Kurdish gnomonic, which means human is more respected in its country of origin than diaspora.
} 
(Is Kurdistan a beautiful country?)

Similar with other languages, it would be more formal if the speaker uses proper and full grammar rules. Also, for non-native speakers, it would be easier to use the key questions for interrogative sentences, and use key exclamatory for exclamatory sentences. This is because they might not be familiar with Kurdish language harmony.

On the other hand, Kurdish sentences may be classified in terms of structure. There is a unified classification among Kurdish linguists that classify Kurdish sentence into three types that mentioned bottom (Amin, 1960; Mirawdali, 2007; H.Rasul, 2005; Mukryani, 2004), however, there might be some minor differences; for example, Abdulla H. Rasul (2005)put both compound and complex sentence in a column, and simple sentence in the other column.

\section{Types of Kurdish sentences in terms of structure:}

1. Simple sentence: It includes at least one noun clause and one verb clause.' (Amin, 2004) Such as;

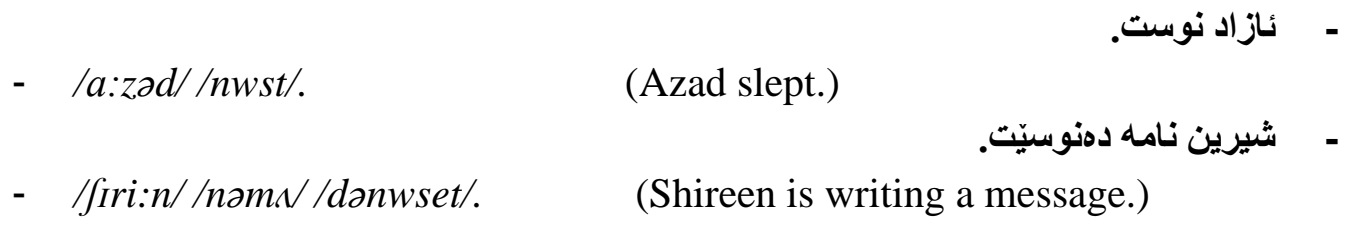

Kurdish simple sentence also could be expanded by adjective, adverb and other compliments. These extra words just make a sentence clearer, and erasing them will not affect the main meaning. Furthermore, it could be made just by one verb with a hidden noun phrase 'zero morpheme', as mentioned earlier.

2. Compound sentence: This kind of sentence consists of two simple sentences or more, the sentences are independent in terms of meaning and grammar. Also, there is a coordinating conjunction, conjunctive adverb or a semicolon between the sentences (H.Rasul, 2005). For example;

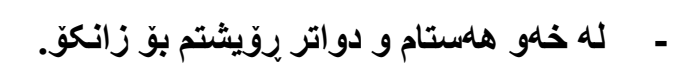

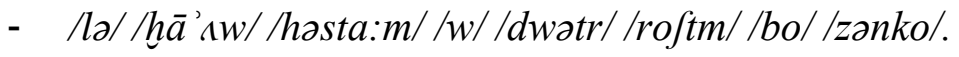

(I woke up and then I went to university.)

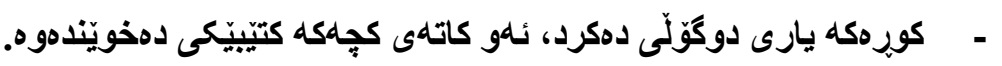

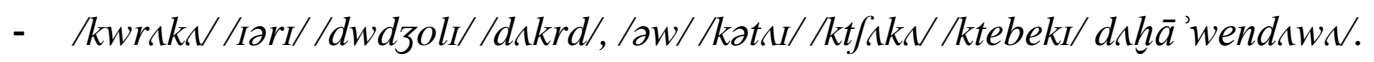
(He was playing football, when she was reading a book.)

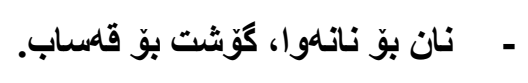

- /nan//bo//nanıwa/, /dzo/t//bo//kasa:b/. 
(Bread is for baker, meat is for butcher ${ }^{4}$.)

3. Complex sentence: 'It is joining two sentences that are different in syntax, one of them is the main sentence, and another one is dependent, relative clauses are making the relationship between both sentences' (A.Omer, 2008). Complex sentences consist of two main parts, which are:

\section{A. Independent clause:}

An independent clause expresses a complete thought. It can be used alone, and there is not any relative clause in front of it (A.Ibrahim, 1980) (Amin N. A., 1960) (Fattah, 1990) (Kakil, 1995) (Mukryani, 2004) (R.Barznji, 2004), for instance;

$$
\text { - }
$$

/sarkawtw//dabi:t/, /adzar//Hä'ot//ma:ndw//bkıi:t/.

(You will succeed, if you work hard.)

$$
\text { - }
$$

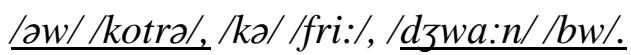

(That pigeon, that flew away, was beautiful.)

\section{B. Dependent (subordinate) clause:}

It is also a part of complex sentence. Although, it has the main parts of sentence such as subject and verb, it cannot be complete and independent without the main clause. It is linked with the independent clause grammatically and semantically (R.Barznji, 2004). Dependent clause always plays a role in the main clause such as 'subject, object...etc'. The grammatical forms and functions of subordinate clause will be clarified in the next section.

/ma:ndzekı/ /nımbi:ni:wə/, /boeə//dldzra:nm/.

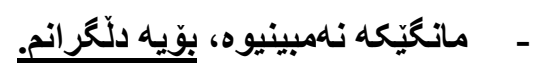

(I have not seen him/her for a month, which is why I am sad.)

$/ \mathrm{d}$ eər ${ }^{\mathrm{r}} \mathrm{N}$, / $\mathrm{k \Lambda} / / \partial \mathrm{w} / / \mathrm{ha} \bar{a}^{\circ} \mathrm{j} \mathrm{i}: / /$ dowet/.

-

(It is obvious, he/she loves her/him.)

Subordinating conjunctions, which are part of subordinate clause, will be explained along with other lexical clauses below.

There are three types of lexical clauses:

\section{Connector}

In Kurdish language, there are some connectors that are used in simple sentences to make a connection between two words within a sentence, (A.Ibrahim, 1980, p. 28). The connector does not have independent meaning (Shwani, 2003, p. 52). For example;

\footnotetext{
${ }^{4}$ Kurdish gnomonic, which basically means that everyone should do its work only.
} 
- $/ \mathrm{mn} / /$ dırom//bo//Hıwler/.

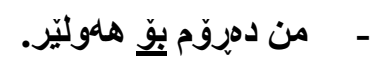

(I will go to Erbil.)

- /mn//bu/tfa:wi://häa'om//bi:ni:m/.

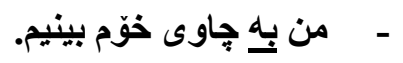

(I saw it by my eyes.)

2. Conjunction

Conjunctions join two sentences or more, which they have different aims, both joint sentences remain independent. This is because conjunctions are not a part of the sentences (Shwani, 2003, p. 54), for example '/w/ (and), /endzə/ (after that), /bələm/ (but)....etc.'

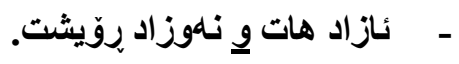

/a:za:d//ha:t/ / $\underline{w} /$ /nawz a:d//roe $\int t /$.

(Azad came and Nawzad went.)

3. Subordinating conjunctions

It is an article that makes a connection between independent and dependent clause. In Kurdish and most other languages, it becomes a part of the dependent clause (R.Barznji, 2004; Shwani, 2003). Also, it might not appear sometimes, in this case a comma or semicolon would be used.

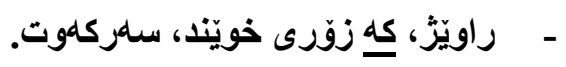

- /ra:wez/, /kı//zori://hä'wend/, /sırkıwt/.

(Rawezh succeded because he studied hard.)

$$
\text { - - ماهو تاريك بوو؛ خوّى كرد به زوردا. }
$$

- /faw//t a:ri:k//bw/2/häoe//krd//bN/zwrd a:/.

(It was a dark night, he/she came in.)

\section{Categorizing Kurdish subordinate clause in terms of grammatical structure}

Generally, there are more than one classification for subordinate clauses in Kurdish. The traditional one has classified Kurdish subordinate clauses semantically. This has resulted partial disagreement among linguists because there are various understanding regarding each sentence. For example, the classification of Nuri A. Amin, who classify subordinate clause into three parts 'noun part, adjective part, adverb part', is different from Kurdistan Mukriani, who classify it into ten parts, and both of them are different with Zare Yusupova (Amin, 1960, p. 51; Mukryani, 2004, pp. 77-88; Yusupova, 2005). To be more accurate, the modern linguists have relied on the syntactical classification, however; some of the semantic spheres are still seen due to the fact that a sentence is also a part of semantics as well (R.Barznji, 2004, p. 65).

In the syntactical classification, subordinate clause has a grammatical role similar to other parts of sentence. There are types of subordinate clauses in Kurdish and their syntactic role: 
1. Subjective subordinate clause

Kurdish is an SOV language, which basically means that the order of Kurdish words in sentence is 'subject + object + verb', for example;

- /a:zad//nams//danwset/.

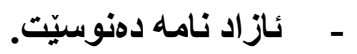

(Azad is writing a letter.)

However, the noun phrases might disappear, but sill clear in terms of meaning because, as been said earlier, Kurdish is an agglutinative language. For example;

- Inams/danwset/.

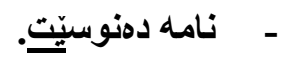

(He/She is writing letter.)

In this sentence agglutinate pronoun has same meaning with subject, so the subject is not appeared. Even, sometimes the agglutinate pronoun is zero morpheme such as;

- /roeft/.

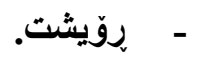

(He/She went.)

As it generally known, a complex sentence consists of a simple independent sentence and a dependent sentence. As previously showed, the simple independent sentence may consist of only a verb. In the previous example, Kurdish speaker knows that the subject is 'he/she'. This case is called zero morpheme.

When, subject is zero morpheme, the subordinate clause would take its role, which is called subjective clause. The subjective clause may take its place after the main clause or it cuts the main clause. This type of the clauses are joint by /-ka/ (Yusupova, 2005, p. 201); for example:

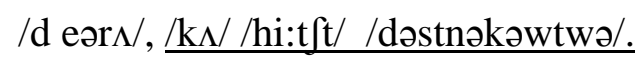

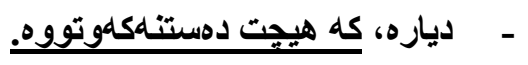

(It is obvious, which you have not got anything.)

Sentence $=$ noun phrase + verbal phrase

Noun phrase $=$ subjective subordinate clause

Verbal phrase $=$ verb

${ }^{5}$ In Central Kurdish dialect, there is not gender differences for pronouns, both (she/he) means / $\Lambda \mathrm{w} /$. 


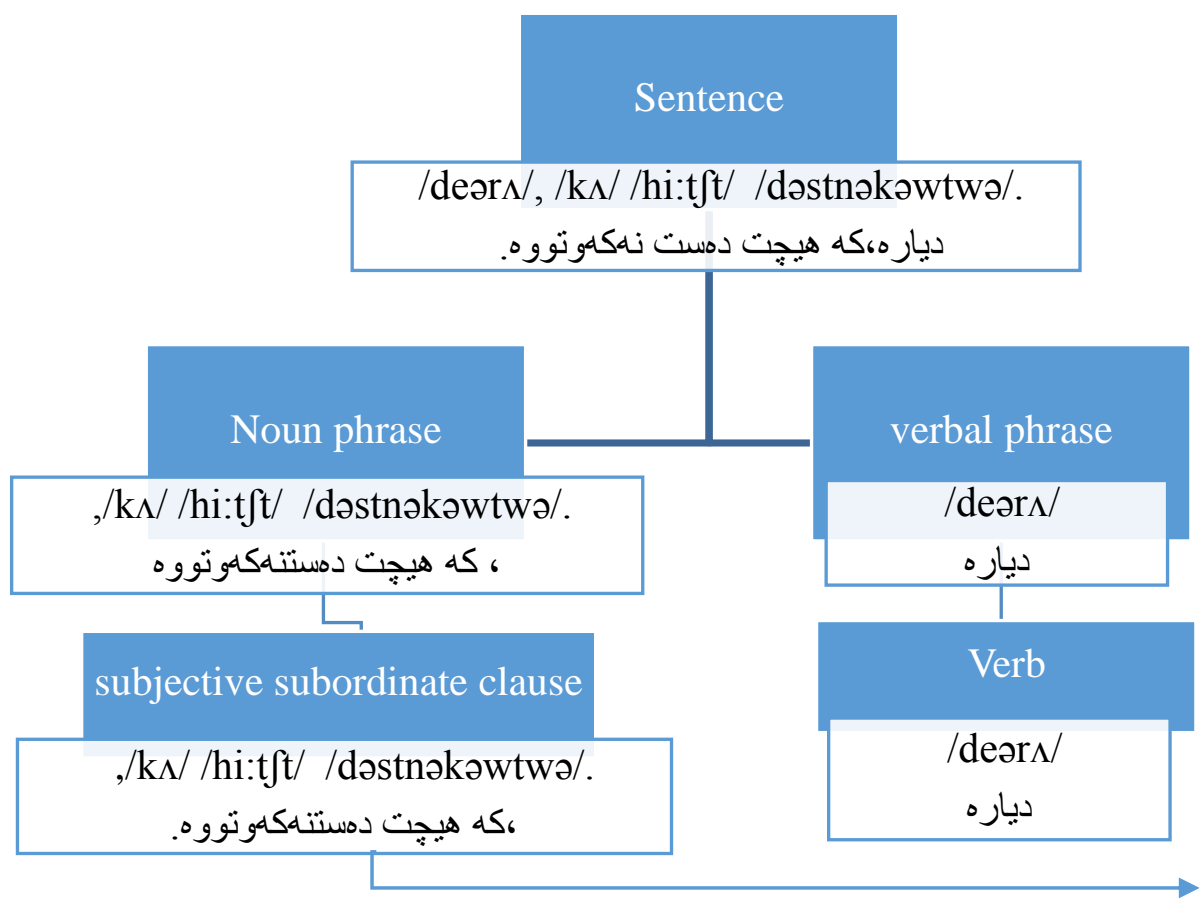

This smart art shows how the changes are made in Kurdish subjective subordinate clause.

In such cases, the grammatical order of Kurdish language would change. In the above example the order is (VSO).

2. Objective subordinate clause

It is clear that objective will appear with transitive verb, for example;

- /fIri:n//nams//danwset/.

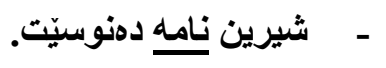

(Shirin is writing a letter.)

Objective also might not appear as an independent word, and it becomes an agglutinate pronoun. Likewise subject, there would be a zero morpheme object. However, object still shows itself in meaning, such as;

$$
\text { - }
$$

/^w//parakai://dawet/. 'Regular sentence with independent subject and object'

/daerwet/.'Sentence with agglutinate pronoun'

- ديـويّت

(He/She wants the money.)

In complex sentence, object might appear as a dependent clause, and the subordinate clause fill the place of object. This is because the main object would become a zero morpheme. (R.Barznji, 2004). In this case, the subordinate clause has the same role as object, and it always comes after the main clause, such as;

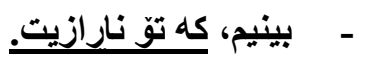


- Ibi:ni:m/, kN/to//na:ra:zit/.

(I saw that you were disagree.)

Sentence $=$ noun phrase + verbal phrase

Noun phrase $=$ zero

Verbal phrase $=$ objective clause + verb

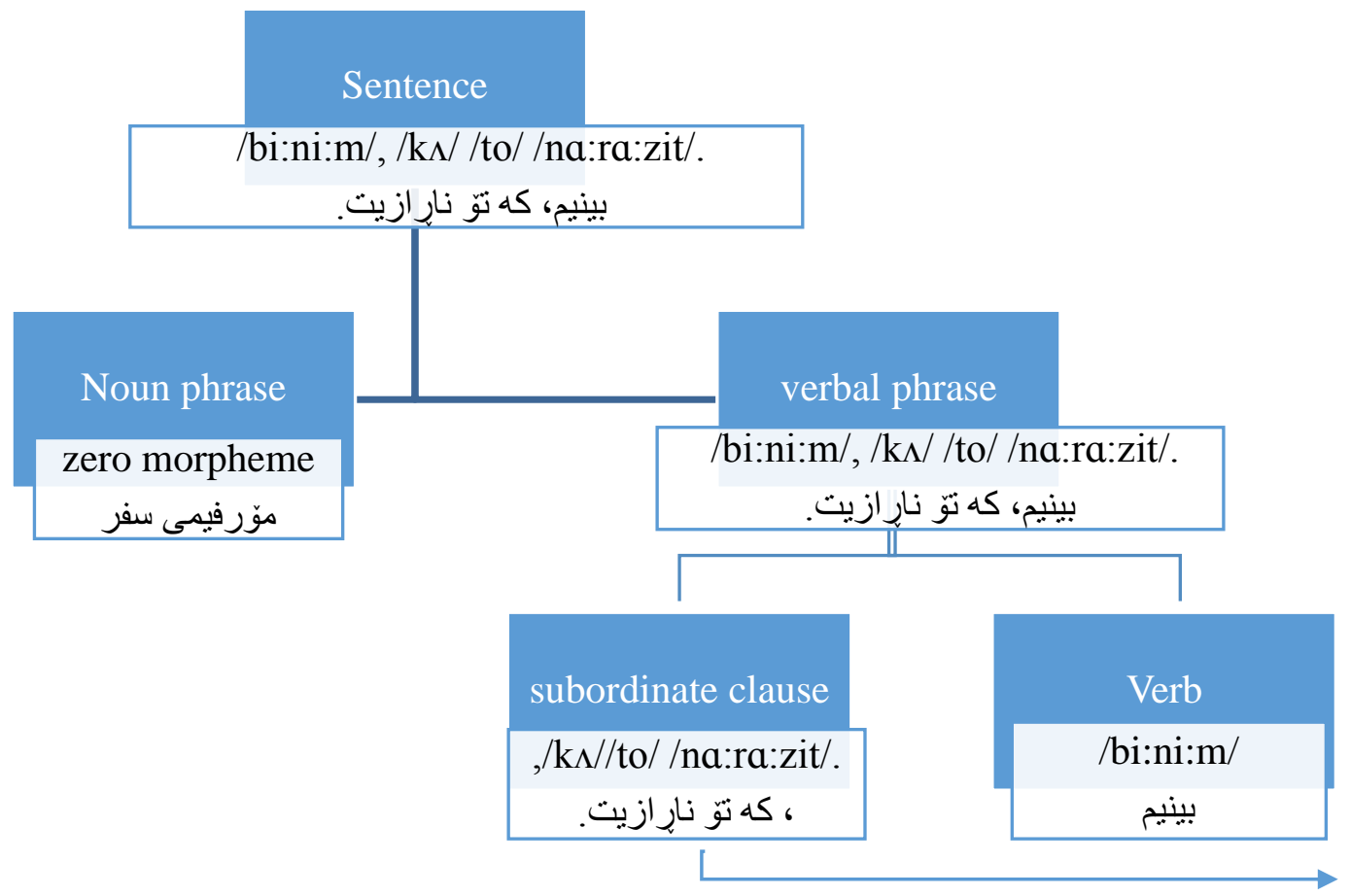

This smart art shows how the changes are made in Kurdish objective subordinate clause.

3. Indirect objective subordinate clause;

Indirect object is to make the meaning of the sentence clearer, and has its syntaxical role, for example;

\section{$/ \mathrm{mn} / / \mathrm{d} \mathrm{t} \mathrm{fm} / \mathrm{ho} /$ /hawler/.}

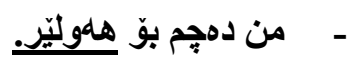

(I will go to Erbil.)

In complex sentence, indirect object would become a full subordinate clause, but has same role with the hidden indirect object in the main clause. Kurdistan Mukriani stated that 'in those complex sentences that main object appears without indirect object, the subordinate clause would take indirect object role, (Mukryani, 2004, p. 15).

Indirect objective clause will come after the main sentence, and there would not be a subordinating conjunction. For example;

$$
\text { - }
$$

- /a:za:d//nıwza:di://na:rdbw/, /kN//bg^remwی.
(Azad had sent Nawzad, in order for return me.) 
Sentence $=$ noun clause + verbal clause

Noun clause $=$ subject

Verbal clause $=$ object + verb + indirect objective subordinate clause

\section{Sentence}

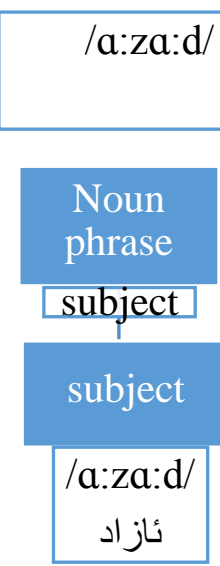

This smart art shows that how the changes are made in Kurdish indirect objective subordinate clause.

4. Determinative subordinate clause

Determiner is a grammatical tool to define a word, phrase or sentence. Also, there should be a word or phrase which has been clarified by the determiner. It is a semantic connection in general, for example;

- /kotreki://

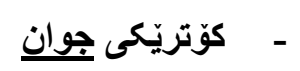

(A beautiful pigeon)

- /da:reki:/ $\underline{\text { barzl }}$

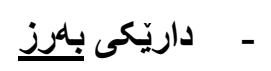

(A tall tree)

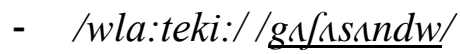

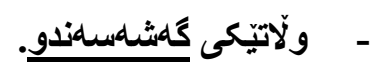

(A developed country)

In complex sentences, sometimes subordinate clause takes determinative role, and it will define a word in the main sentence. So, this subordinate clause is called determinative subordinate clause (H.Rasul, 2005; Mukiryani, 2002). It takes the 
grammatical role of the defined noun in the main clause. There are some forms of determinative subordinate clauses;

\section{A. Determinative subordinate clause that define subject}

There is a subject in the main clause, and it will be more defined, and it will becomes clearer by a subordinate clause, for example;

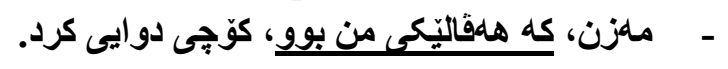

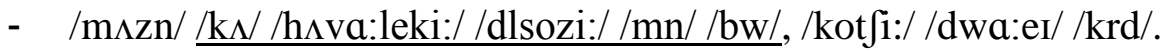

(Mazn, who was one of my best friends, passed away.)

B. Determinative subordinate clause that defines object

$$
\text { - }
$$

- /nw//mnda:leki://hen a://kN//zor//rw//hä'o///bw/.

(He brought the child who was very lovely.)

\section{-}

- /da:rek//brwens/, /kN/krmel/nabet/.

(Grow a tree that is not affected by worm ${ }^{6}$.)

In both sentences (/mnda:leki:/ and /da:rek/) are object, and they were made clearer by the subordinate clauses.

C. Determinative subordinate clause that defines indirect object

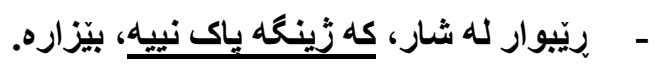

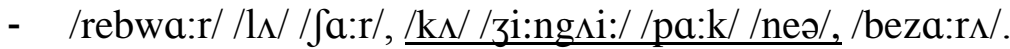

(Rebwar is bored with city where the weather is polluted.)

In this sentence the subordinate clause determine / $\mathrm{fa}: \mathrm{r} /$, which is indirect object.

\section{Determinative subordinate clause that defines a compliment}

This kind of subordinate clauses determine a compliment in the main sentence, for example in the following sentence, the subordinate clause determine /dzenosard/ in the main sentence, which is a compliment.

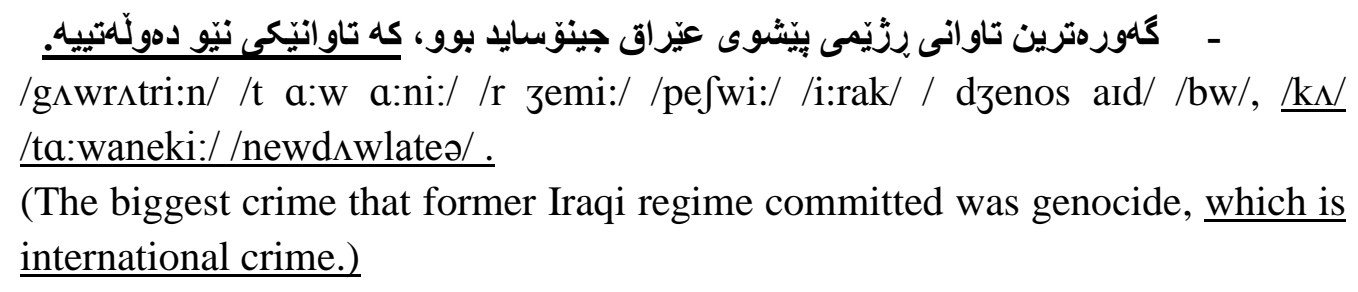

(The biggest crime that former Iraqi regime committed was genocide, which is international crime.)

\footnotetext{
${ }^{6}$ Kurdish gnomonic that means the groups 'in particular national groups' will be defeated when a member of them is disloyal.
} 


\section{E. Determinative clause that defines determinative in main sentence}

It determines a word that is determinator in the main clause. For example in the following sentence, /slemani:/ determined the place of $/ \mathrm{r} \Lambda \int \Lambda \mathrm{ber} /$, and the subordinate clause determined /slemani:/.

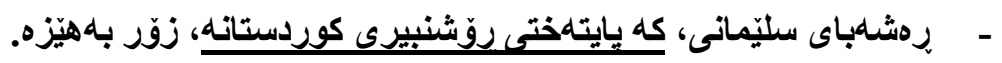

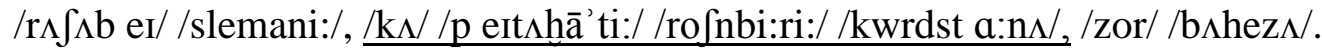

The wind of Sulaimani where is the cultural capital of Kurdistan, is very strong.

\section{CONCLUSION}

In conclusion, it would important to know that each language has its sphere, and one cannot apply the definitions that were written for English language on Kurdish language. It is also true for other languages. Kurdish is an agglutinative language, and it is possible to make a Kurdish sentence in only one word that have proper and complete meaning because of having zero morpheme. There are two main classifications for Kurdish sentence, one of them classify sentences in terms of meaning, and another one is classify sentences in terms of grammatical structure. Both of them play their roles, however, classification in terms of grammar would be more accurate, in particular for those people who want to learn the language. Also, each type of sentence has its lexical clauses.

Regarding complex sentence, the classification of subordinate sentence in terms of grammatical structure is more accurate, because the other classifications could not be unified, and grammar is generally not vague. So that each dependent clause has its grammatical role and make a word or a morpheme within independent clause clearer. As such, one can find the connection between the two sentences, define the types of Kurdish subordinate clauses, differentiate them, and use complex sentences easily in a correct way.

\section{REFERENCES}

A.Ibrahim, I. (1980). Compound affiliated sentence and compound determinative sentence in central dialects of Kurdish language (in Kurdish). Baghdad: First edition.

A.Omer, N. (2008). causative in Kurdish language (in Kurdish). Koya: Master dissertation in Koya University-Kurdish department.

Amin, N. A. (1960). Kurdish Grammar (in Kurdish). Sulaimanya: First edition.

Amin, W. O. (2004). More things about linguistics (in Kurdish). Erbil: Aras Publications.

Bybee, J. L. (2002). Main clauses are innovative, subordinate clauses are conservative. In M. N. Joan L. Bybee, Complex Sentences in Grammar and Discourse; Essays in honor of Sandra A. Thompson (pp. 1-17). University of New Mexico / University of Wisconsin at Milwaukee. 
Fattah, M. M. (1990). Linguistics (in Kurdish). Erbil: Salhaddin University.

H.Rasul, A. (2005). A gist of Kurdish syntax (in Kurdish). Sulaimani: 1st edition.

Kakil, Q. (1995). Types of sentence and theories of speaking (In Kurdish). Erbil: Salahaddin University 'Master thesis'.

Mirawdali, K. (2007). Kurdish language dictionary (in Kurdish). Sulaimani: 1st edition.

Mukiryani, K. (2002). Kurdish syntax; the simple sentence (In Kurdish). Erbil.

Mukryani, K. (2004). Complex sentence syntax (In Kurdish). Erbil: First edition.

Oxford-dictionary. (2015, April 23). Oxford Dictionaries. Retrieved from Oxford University Press: http://www.oxforddictionaries.com/definition/english/sentence

R.Barznji, S. (2004). The rules of subordinate clause (in Kurdish). Erbil: PhD thises.

Shwani, R. M. (2003). Lexical clauses in Kurdish language (PhD thesis in Kurdish). Sulaimani: Sardam publishing house.

Yusupova, Z. (2005). Sulaimani variation of Kurdish language (translated into Kurdish from Russian by Kurdistan Mukriani). Erbil: 1st edition. 